\title{
O EMPREGO DE POLÍMEROS EM REVESITMENOS HIDROFÓBICOS, SUPER-HIDROFÓBICOS E AUTOLIMPANTES: UMA REVISÃO DA LITERATURA
}

\author{
THE USE OF POLYMERS IN HYDROPHOBIC, SUPER-HYDROPHOBIC AND \\ SELF-CLEANING COATINGS: A LITERATURE REVIEW
}

\author{
Alex Glier ${ }^{1}$ e Rafael Sheer Trindade ${ }^{2}$
}

\section{RESUMO}

O presente artigo é uma revisão bibliográfica sobre revestimentos poliméricos hidrofóbicos, super-hidrofóbicos e autolimpantes, bem como aplicações, métodos de produção e a evolução das pesquisas relacionadas ao tema. Recentemente, várias instituições de ensino e indústrias vêm mostrando um grande interesse sobre esses revestimentos, pois modificando a molhabilidade superficial de alguns substratos, podemos encontrar novas aplicações devido a alterações nas propriedades como maior resistência a corrosão de metais, melhorando a visibilidade em vidros em condições climáticas adversas, conservação e revestimento de alimentos e a obtenção de superfícies livres de contaminantes, como no caso das superfícies autolimpantes. Assim, o objetivo desde trabalho foi realizar uma pesquisa exploratória de caráter bibliográfica relacionadas ao assunto, a fim de analisar alguns dos métodos de obtenção dos revestimentos poliméricos, principais aplicações e a evolução da pesquisa sobre as superfícies hidrofóbicas nos últimos anos e os países que mais se destacam dentre o assunto. Baseado nas pesquisas realizadas existem inúmeras formas de produzir superfícies hidrofóbicas, super-hidrofóbicas ou autolimpantes usando revestimentos poliméricos. Além disso, também é possível modificar a superfície dos polímeros para a obter-se maiores ângulos de contato.

Palavras-chave: revestimentos poliméricos, métodos de produção, aplicações, evolução, molhabilidade.

\section{ABSTRACT}

This article is a bibliographic review on hydrophobic, super-hydrophobic and self-cleaning polymeric coatings, some of their applications, production methods and the evolution of research related to the theme. Recently, several educational institutions and industries have shown great interest in these coatings because by modifying the surface wettability of a substrate we can find new applications for materials since some of its properties were altered such as greater resistance to corrosion of metals, improved visibility in glass in adverse weather conditions, conservation and coating of food and obtaining surfaces free of contaminants, as in the case of self-cleaning surfaces. Thus, the objective of this work was to analyze publications related to the subject and to analyze some of the existing methods of obtaining polymeric coatings, their main applications, as well as the way in which research on hydrophobic surfaces have been evolving in recent years and the countries that most stand out among the subject. From that research, many procedures to obtain hydrophobic, super-hydrophobic and self-cleaning surfaces were found by applying polymeric coatings.

Keywords: polymeric coatings, production methods, applications, evolution, wettability.

\footnotetext{
${ }^{1}$ Acadêmico do curso de Engenharia de Materiais - Universidade Franciscana. E-mail: alexglier95@gmail.com

${ }^{2}$ Orientador - Universidade Franciscana. E-mail: rafael.trindade@ufn.edu.br
} 


\section{INTRODUÇÃO}

Nos últimos anos, revestimentos hidrofóbicos, super-hidrofóbicos e autolimpantes vêm ganhando espaço tanto em pesquisas acadêmicas, quanto em aplicações industriais (Souza, 2018). Modificando as características da superfície de um determinado material, podemos encontrar novas aplicações para este, ou ainda melhorar sua durabilidade, reduzindo custos de produção e de manutenção (SOUZA, 2018).

Como exemplo, temos tratamentos superficiais realizados em metais com o objetivo de diminuir o ângulo de contato entre a água e a superfície, reduzindo a área de contato do líquido com o metal, tornando-o menos suscetível a oxidação (Oliveira, 2011). Assim, esses revestimentos possuem inúmeras utilidades quando aplicados sobre o vidro, com o melhorando a visibilidade e transparência em condições climáticas adversas, podendo ser aplicados em janelas de prédios, vidros automotivos, box de banheiros, placas de captação de energia solar, dentre outros (Oliveira, 2011).

Os revestimentos hidrofóbicos, super-hidrofóbicos e autolimpantes podem ser obtidos a partir de inúmeros materiais e por meio de variados processos de produção (Viechineski, 2015). Os polímeros já são largamente empregados como matéria-prima para a obtenção destes revestimentos, devido ao baixo custo do material e processamento, na grande maioria das vezes, simples. Este artigo é dividido em duas partes. A primeira introduz conceitos teóricos de hidrofobicidade, ângulo de contato e superfícies autolimpantes. A segunda parte traz pesquisas acadêmicas relacionadas ao tema, para que seja possível compreender melhor a sua importância, as principais aplicações, principais métodos de obtenção e a evolução das pesquisas relacionadas a revestimentos poliméricos hidrofóbicos.

\section{SUPERFÍCIES HIDROFÓBICAS}

Conforme Fowkes (1969), uma superfície é hidrofóbica quando a água não se espalha sobre ela, ou seja, permanece sobre a superfície em forma de gota (esfera) e um alto ângulo de contato pode ser traçado a partir do plano da superfície, tangenciando a gota d'água. Para obtenção de uma superfície hidrofóbica deseja-se o maior ângulo de contato possível.

Segundo Yuan e Lee (2013), uma gota de qualquer líquido possui um formato esférico ou parcialmente esférico devido a tensão superficial do líquido. As moléculas de um líquido puro são atraídas pelas moléculas vizinhas com a mesma intensidade em todas as direções, ocasionando uma força de equilíbrio no interior do líquido. Contudo, as moléculas que estão posicionadas nas extremidades do líquido não possuem moléculas vizinhas para satisfazer esse equilíbrio. Desta forma, essas moléculas superficiais são atraídas para o interior da gota pelas suas moléculas vizinhas, causando uma pressão interna e faz com que o líquido contraia a sua superfície, geralmente em formato esférico, formato que mantém uma menor energia livre de superfície (Yuan e Lee, 2013). A Figura 1 apresenta a tensão superficial de um líquido e das forças internas de ligação entre as moléculas. 
Figura 1 - Representação da tensão superficial de um líquido e das forças internas de ligação entre as moléculas.

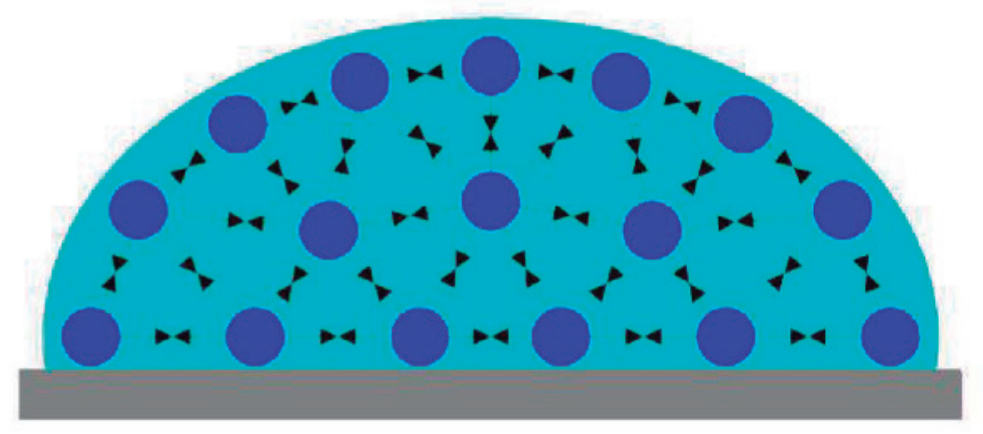

Fonte: Verplannck (2007).

\section{ÂNGULO DE CONTATO}

De acordo com Law e Zhao (2015), o ângulo de contato de uma gota de qualquer líquido é um equilíbrio mecânico entre as tensões superficiais do líquido, do sólido e da interação interfacial líquido-sólido. Esse equilíbrio foi definido por Thomas Young, a cerca de 200 anos atrás, bem como a equação para determinar o ângulo de contato, conforme a Eq. (1).

Equação 1 - Equação de Young, onde " $\gamma_{\mathrm{SV}}$ " é a tensão superficial do sólido, " $\gamma_{\mathrm{LV}}$ " a tensão superficial do líquido,

" $\gamma_{\mathrm{SL}}$ " a tensão superficial da interação interfacial líquido-sólido e " $\Theta$ " o ângulo de contato.

$$
\begin{gathered}
\gamma_{S V}=\gamma_{L V} \cdot \cos \theta+\gamma_{S L} \\
\text { Fonte: Law e Zhao (2015). }
\end{gathered}
$$

A Figura 2 apresenta o ângulo de contato, formado entre o sólido, o líquido e a interface líquido-sólido.

Figura 2 - Representação do ângulo de contato baseado na equação de Young.

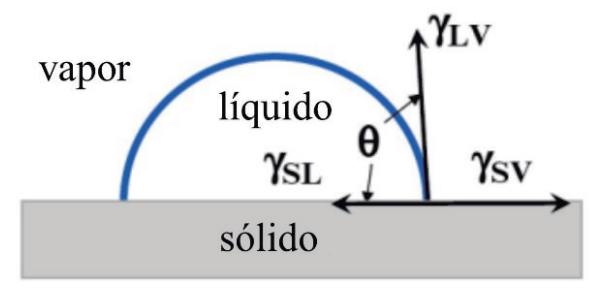

Fonte: Law e Zhao (2015).

O ângulo de contato consiste na intersecção de três fases, um líquido (geralmente água), um sólido e um gás (ar). Além disso, quanto maior o ângulo de contato, menor é a interação que existe entre o líquido e o sólido (Souza, Braga e Sosnik, 2015). As superfícies podem ser classificadas entre super-hidrofílicas até super-hidrofóbicas, conforme o ângulo de contato, conforme a Figura 3. 
Figura 3 - Classificação de molhabilidade de acordo com o ângulo de contato.

\begin{tabular}{|c|c|c|c|c|}
\hline Regime & $\begin{array}{l}\text { Super- } \\
\text { hidrofilico }\end{array}$ & Hidrofílico & Hidrofóbico & $\begin{array}{l}\text { Super- } \\
\text { hidrofóbico }\end{array}$ \\
\hline $\begin{array}{l}\text { Diagrama } \\
\text { da gota }\end{array}$ & & & & \\
\hline $\begin{array}{l}\text { Ângulo } \\
\text { de } \\
\text { contato }\end{array}$ & $\theta<10^{\circ}$ & $\theta<90^{\circ}$ & $\theta>90^{\circ}$ & $\theta>150^{\circ}$ \\
\hline
\end{tabular}

Fonte: Oliveira (2011).

\section{SUPERFÍCIES AUTOLIMPANTES}

Segundo He (2017), as superfícies autolimpantes são geralmente definidas pela capacidade do material em manter sua superfície livre de contaminantes, evitando a deposição de sujeiras. Existem basicamente dois tipos de superfícies autolimpantes: super-hidrofóbicas e super-hidrofílicas. Neste artigo serão consideradas apenas as superfícies autolimpantes obtidas em superfícies super-hidrofóbicas.

Daoud (2013) afirma que um dos mecanismos das superfícies autolimpantes está vinculado com a maneira como a gota d'água se move sobre tal superfície. Uma gota numa superfície com um alto ângulo de contato pode rolar sobre ela ao invés de deslizar. Esse fenômeno permite com que as partículas presentes na superfície do material sejam coletadas durante o movimento de rolamento da gota.

A Figura 4 apresenta o efeito do rolamento da gota sobre uma superfície, onde podemos observar uma superfície comum a esquerda, na qual a gota d'água desliza sobre a superfície e não remove as impurezas desta. Ao lado direito temos uma superfície super-hidrofóbica, onde a gota rola sobre a mesma, extraindo os contaminantes e limpando-a, assim, essa superfície pode ser dita autolimpante.

Figura 4 - Efeito do rolamento da gota sobre uma superfície promovendo a remoção de impurezas.

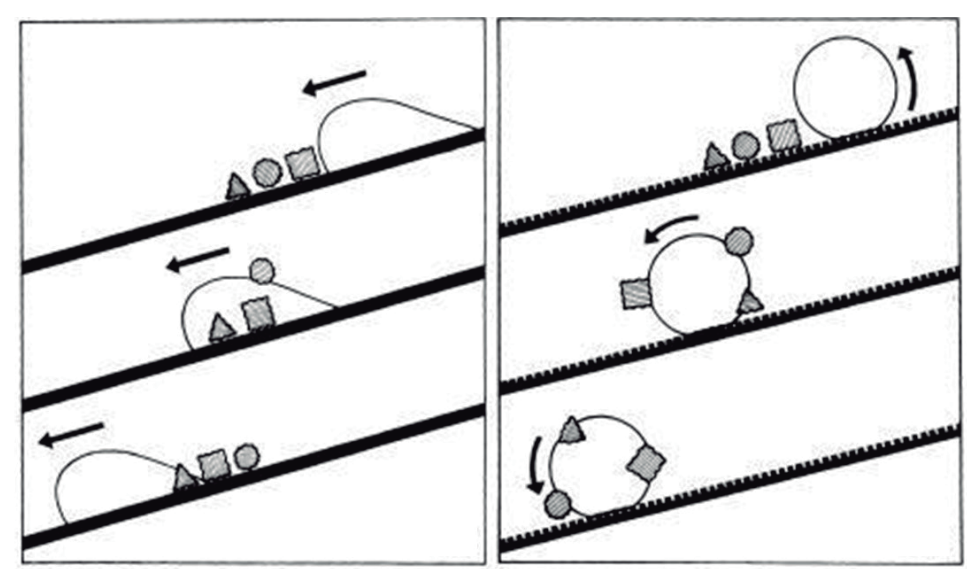

Fonte: Nanomateriais. 


\section{POLÍMEROS EM REVESTIMENTOS HIDROFÓBICOS E SUPER-HIDROFÓBICOS}

Souza (2018) analisou a deposição de filmes poliméricos finos com micro-jatos atmosféricos sobre substratos de vidro, utilizando o polímero hexametildisiloxano (HMDSO), como precursor. A técnica utilizada para a deposição do filme foi a deposição à vapor químico assistido por plasma (PECVD). A técnica de PECVD consiste na aplicação de uma descarga luminescente para a produção de filmes finos, por meio de monômeros fragmentados e recombinados, depositados sobre uma superfície dentro de um reator. Ainda, durante esse procedimento, as moléculas dos monômeros recebem energia por meio de colisões inelásticas, causando a fragmentação das mesmas, gerando espécies reativas que tendem a se recombinar na forma de filmes ou pós que são depositados no substrato próximo a descarga de plasma (Souza, 2018). Este processo gera filmes homogêneos, uniformes e com boa aderência a diversos tipos de substratos.

O dispositivo para aplicação da técnica foi construído em latão e tubos de poliacetal, em formato cilíndrico conectados em um Erlenmeyer e uma fonte de tensão, conforme a figura 5. O gás inerte utilizado no processo foi o argônio.

Figura 5 - Dispositivo utilizado na técnica PECVD.
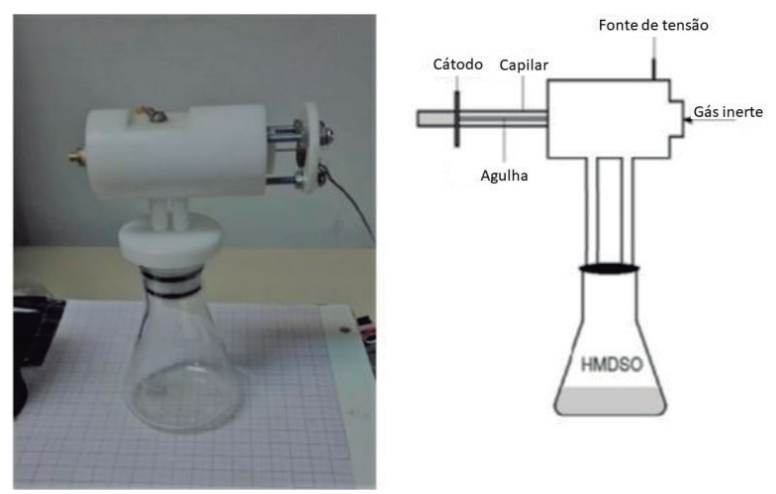

Fonte: Souza (2018).

O HMDSO, monômero utilizado como precursor, é incolor, muito volátil em condições normais, atóxico, tem baixo custo, não solúvel em água (porém é solúvel em solventes orgânicos), alta viscosidade e estabilidade a baixas e a altas temperaturas (Souza, 2018). O filme polimérico foi caracterizado por meio da técnica de ângulo de contato, onde obteve-se valores acima de $90^{\circ}$, possibilitando a obtenção de um filme polimérico hidrofóbico sobre o substrato de vidro.

Viechineski (2015) preparou um filme polimérico hidrofóbico utilizando o polímero policloreto de vinila (PVC), parafina e nitrobenzeno como solvente. A solubilização do polímero foi realizada na proporção de 1 grama de PVC para 66 mililitros de nitrobenzeno a temperatura de $170^{\circ} \mathrm{C}$ e agitação de $500 \mathrm{rpm}$. Após a dissolução do polímero, adicionou 21 gramas de cera de parafina, mantendo a agitação e a temperatura constantes até a solubilização total. 
A aplicação do produto obtido foi feita por meio de borrifamento sobre a superfície do vidro e o excesso retirado com o auxílio de um pano macio. Na produção do filme, o polímero utilizado foi na forma de filme, com pureza de 69,44\%, e o solvente com pureza de 99,5\%. Após a aplicação, o vidro com a película polimérica não apresentou nenhuma alteração visual quanto a transparência.

O revestimento polimérico passou pelas análises de ângulo de contato, ângulo de escoamento e microscopia eletrônica de varredura (MEV). Para a determinação do ângulo de contato, foi analisado uma imagem obtida por câmera digital de uma gota de água sobre a superfície do vidro revestido. A medição do ângulo foi realizada por meio de software computacional, no qual se determinou um ângulo de contato de $102^{\circ}$. O ângulo de escoamento foi avaliado por meio da medida da inclinação da placa de vidro necessária para iniciar o escoamento da gota de água. Para o revestimento polimérico, foram obtidos ângulos de escoamento de $7^{\circ}$. As microscopias obtidas por MEV comprovaram uma espessura aproximada de $156 \mathrm{~nm}$ do revestimento polimérico e uma distribuição uniforme do mesmo sobre a superfície do vidro.

Conforme Araújo (2017), foi possível depositar filmes super-hidrofóbicos nanoestruturados de politetrafluoretileno (PTFE) e nanopartículas de óxido de cálcio ( $\mathrm{NPSCaO}$ ) por deposição por espuma sobre superfícies de fibra de poliácido láctico (PLA). O revestimento foi aplicado sobre um tecido de malha Jersey $100 \%$ PLA com $150 \mathrm{~g} \mathrm{~m}^{-2}$ e o agente espumante utilizado foi o sulfato de lauril éter de sódio.

As amostras de PLA passaram por um pré-tratamento onde foram submetidas a um banho em solução de detergente não iônico e $\mathrm{NaOH}$. Na sequência foram lavadas com água corrente para retirar o excesso de produtos químicos. O procedimento experimental foi repetido 20 vezes, variando os parâmetros de concentração de NPsCaO, concentração de PTFE, temperatura de polimerização e tempo de polimerização, de acordo com a tabela 1.

Tabela 1 - Planejamento experimental.

\begin{tabular}{|c|c|c|c|c|}
\hline Corridas & $\begin{array}{l}\text { Concentração de } \\
\text { NPsCaO (\%spm) }\end{array}$ & $\begin{array}{l}\text { Concentração } \\
\text { de PTFE }(g / L)\end{array}$ & $\begin{array}{c}\text { Temperatura de } \\
\text { polimerização }\left({ }^{\circ} \mathrm{C}\right)\end{array}$ & $\begin{array}{c}\text { Tempo de } \\
\text { polimerização }(s)\end{array}$ \\
\hline 1 & 0,6 & 20 & 140 & 90 \\
\hline 2 & 0,4 & 50 & 130 & 60 \\
\hline 3 & 0,6 & 80 & 140 & 90 \\
\hline 4 & 0,6 & 80 & 120 & 90 \\
\hline 5 & 0,6 & 80 & 120 & 30 \\
\hline 6 & 0,6 & 80 & 140 & 30 \\
\hline 7 & 0,4 & 50 & 130 & 60 \\
\hline 8 & 0,2 & 80 & 140 & 90 \\
\hline 9 & 0,2 & 20 & 140 & 30 \\
\hline 10 & 0,2 & 20 & 120 & 30 \\
\hline 11 & 0,2 & 80 & 140 & 30 \\
\hline 12 & 0,2 & 20 & 140 & 90 \\
\hline 13 & 0,2 & 80 & 120 & 30 \\
\hline 14 & 0,6 & 20 & 120 & 90 \\
\hline
\end{tabular}




\begin{tabular}{lllll}
15 & 0,2 & 20 & 120 & 90 \\
\hline 16 & 0,6 & 20 & 120 & 30 \\
17 & 0,4 & 50 & 130 & 60 \\
18 & 0,2 & 80 & 120 & 90 \\
19 & 0,4 & 50 & 130 & 60 \\
20 & 0,6 & 20 & 140 & 30 \\
\hline
\end{tabular}

Fonte: Araújo (2017).

As espumas, nas diversas concentrações de $\mathrm{PTFE} / \mathrm{NPsCaO}$, foram produzidas com o apoio de um agitador mecânico e aplicadas sobre as amostras por meio de uma espátula. Após a aplicação da espuma, as amostras foram secadas por $100^{\circ} \mathrm{C}-3$ minutos, e na sequência passaram pelo processo de polimerização conforme os parâmetros mencionados na Tabela 1. Depois da polimerização, as amostras passaram pelos ensaios de ângulo de contato, transmitância óptica, repelência a líquidos, solidez à lavagem, dentre outros.

Após a caracterização dos revestimentos obtidos, notou-se que o parâmetro mais importante durante os ensaios foi a temperatura de polimerização, seguido pelo tempo de polimerização. Todas as amostras obtivem um ângulo acima de $138^{\circ}$ no ensaio de ângulo de contato, porém a configuração que apresentou o melhor resultado foi a da corrida $\mathrm{n}^{\mathrm{o}} 3$, com $159,67^{\circ}$. Com o objetivo de analisar a transparência dos revestimentos, foram preparadas lâminas de vidro com o revestimento de PTFE, PTFE/NPsCaO e uma lâmina sem revestimento. As lâminas foram testadas em um espectrofotômetro UV-Visível. A lâmina sem nenhum revestimento obteve uma transmitância óptica de $91 \%$, enquanto que as placas revestidas com PFTE e PFTE/NPsCaO tiveram uma transmitância de 90 e de $88 \%$ respectivamente.

A repelência à líquidos das amostras foram avalizadas à luz da norma AATCC 193-2007, que determina a eficácia de um revestimento com baixa energia de superfície em todos os tipos de tecidos, avaliando a resistência ao umedecimento. Está norma consiste em testar as amostras com gotas de líquidos padrão com uma série de soluções contendo água/álcool, alterando a tensão superficial do líquido. Neste teste os revestimentos obtiveram nota máxima, confirmando assim o efeito obtido com o tratamento. A elevada repelência à líquidos do revestimento confere a este a capacidade de autolimpeza, onde a sujeira é facilmente removida pela água.

As amostras revestidas também passaram por 5 ciclos de lavagem, de acordo com a norma AATCC 61-2003, onde cada ciclo de lavagem equivale a 5 lavagens domésticas, e 100 ciclos de abrasão, seguindo os parâmetros da norma ASTM D4966, que consiste em submeter a amostra a movimentos circulares de fricção a uma pressão de $9 \mathrm{kPa}$. O ensaio de solidez a lavagens indicou que o tecido de PLA revestido com PTFE/NPsCaO conseguiu manter um alto ângulo de contato, caracterizando uma superhidrofobicidade, mesmo após 25 ciclos de lavagem doméstica. Já durante o ensaio de abrasão, as amostras conseguiram manter suas características super-hidrofóbicas mesmo submetidas a 100 ciclos de abrasão. 


\section{MODIFICAÇÕES SUPERFICIAIS EM POLÍMEROS}

Avanci (2018) obteve superfícies com propriedades super-hidrofóbicas por meio da modificação superficial do polietileno (PE) recobrindo com nanopartículas de $\mathrm{TiO}_{2}\left(\mathrm{NPsTiO}_{2}\right)$ por meio de imersão, sendo que as variáveis de temperatura e tempo de imersão e concentração da solução foram definidas durante o procedimento experimental.

Os corpos de prova foram produzidos a partir de grãos (pellets) de polietileno de alta, média e baixa densidade (PEAD, PEMD, PEBD), em formatos retangulares de 2x1 cm. Antes do recobrimento, as placas de PE passaram por um banho de ultrassom com hexano, clorofórmio e isopropanol, e na sequência foram secadas em estufa à vácuo por $24 \mathrm{~h}$ na temperatura de $70^{\circ} \mathrm{C}$ para a retirada de impurezas. Ainda antes da imersão dos polímeros na solução contendo as $\mathrm{NPsTiO}_{2}$, as amostras passaram por uma análise de imersão em xileno puro.

A imersão em xileno puro visa aumentar a área exposta na fase amorfa do PE, permitindo um maior contato entre a superfície do polímero com as NPs. Quando em contato com o xileno, o PE tende a inchar, devido a difusão das moléculas do solvente para dentro da massa polimérica. É nessa fase que ocorre o ancoramento do agente de acoplamento, e por consequência a adesão das NPs, pois as cadeias do polímero se encontram abertas. Para tal, foram necessários testes de imersão em xileno para determinar a temperatura e o tempo de imersão ideal para a obtenção do polímero inchado. Foram feitos testes a temperaturas de $110^{\circ}, 120^{\circ}$ e $130^{\circ} \mathrm{C}$ e tempos de $5,10,15$ segundos e 1 minuto em cada temperatura. As configurações que se mostraram mais adequadas para a obtenção do polímero inchado foram na temperatura de $110^{\circ} \mathrm{C}$, e nos tempos de 5,10 e 15 segundos.

Após os testes realizados com o xileno, foram preparadas as soluções utilizadas para a imersão. Primeiramente foi preparado uma solução padrão (SP), na proporção de 95/5\%v/v de xileno e trimetoxipropil-silano. A essa mistura adicionou-se $1 \% \mathrm{~m} / \mathrm{v}$ de $\mathrm{TiO}_{2}$. A SP foi utilizada no preparo das soluções avançadas (SPA), nas proporções de 5\%,10\%, 20\% e 50\%v/v de n-hexadecano. Essas soluções foram denominadas de SPA5, SPA10, SPA20 e SPA50, respectivamente. O n-hexadecano foi adicionado à SP com o objetivo de aumentar a interação do agente de acoplamento (trimetoxipropil-silano) com a superfície do polímero, facilitando assim, a fixação das $\mathrm{NPsTiO}_{2}$, uma vez que a composição química deste hidrocarboneto é similar à do substrato. Os revestimentos por imersão foram realizados a temperatura de $110^{\circ} \mathrm{C}$, nos tempos de 5, 10 e 15 segundos. Após a imersão, os corpos de prova foram secos em estufa à vácuo a $70^{\circ} \mathrm{C}$ por $24 \mathrm{~h}$.

Todas as amostras de PE apresentaram ângulos de contato menores do que $110^{\circ}$ antes de serem tratadas com as soluções preparadas para o recobrimento. Após passarem pela imersão na SP as placas obtiveram um aumento considerável de ângulo de conato, sendo que o maior ganho em hidrofobicidade foi obtido no PEBD, que alcançou o valor de $137,81^{\circ}$ quando tratado por 5s na SP à temperatura de $110^{\circ} \mathrm{C}$. Já quando tratadas com as SPA, todos os corpos de prova obtiveram ângulos 
de contato acima de $150^{\circ}$, o que caracteriza uma superfície super-hidrofóbica. Observou-se também que a medida que se aumentava a concentração de n-hexadecano, os valores de ângulo de contato também aumentaram, conforme a figura 6, o que comprova que o hidrocarboneto empregado na solução foi fundamental na fixação das $\mathrm{NPsTiO}_{2}$. Por meio de microscopia de força atômica pode-se ainda determinar a espessura dos filmes depositados sobre as amostras, que obtiveram espessuras médias de 28,313 a $40,518 \mu \mathrm{m}$.

Figura 6 - Ângulos de contato obtidos para o PEBD após imersão por 10 s a $110^{\circ} \mathrm{C}$ nas soluções A) SPA5; B) SPA20; C) SPA50.

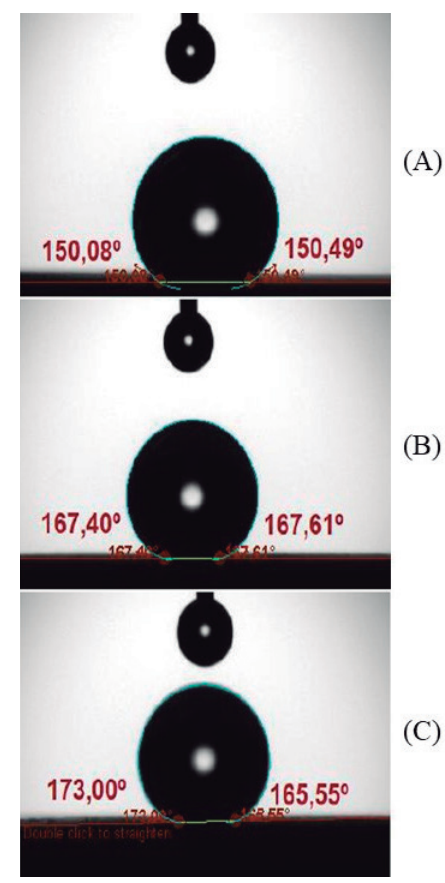

Fonte: Avanci (2018).

Gama (2014) afirma que é possível alterar o ângulo de contato de polímeros biodegradáveis naturais e de blendas poliméricas por meio de modificações superficiais do mesmo. Em seu experimento, o autor alterou a topografia da superfície de polímeros antes hidrofílicos, como o amido de mandioca termoplástico e suas blendas, gerando superfícies super-hidrofóbicas, com elevados ângulos de contato.

O amido termoplástico, bem como blendas com polietileno de baixa densidade (PEBD) nas proporções de 25, 50 e 75\% (em massa), tiveram a topografia e a química de suas superfícies modificadas com a inserção de microcomponentes e nanocomponentes. Os filmes poliméricos e suas blendas foram decorados com microcomponentes como: espongilito, fibra de vidro, esferas ocas de vidro e microesferas de poliestireno 2-aminoetil. Para serem depositados, os microcomponentes foram dispersos em etanol e em seguida gotejados sobre as amostras de amido a $80^{\circ} \mathrm{C}$. Também foram utilizadas nanofibras de policaprolactona (PCL) na decoração do filme polimérico, por meio da técnica de electrospinning. 
Na técnica de caracterização de ângulo de contato o amido sem a modificação superficial apresentou valores entre 42 e $60^{\circ}$. Já para as blendas poliméricas de amido e PEBD os valores obtidos foram de $78^{\circ}$ para o amido/PEBD (25/75) e de $75^{\circ}$ para o amido/PEBD (50/50) e (75/25).

Após o tratamento superficial das amostras notou-se que os substratos tratados com espongelito e esferas ocas de vidro permitiram a alteração da molhabilidade para ângulos de contato acima de $100^{\circ}$. Além disso, também foram observados baixos ângulos de histerese, o que possibilita a geração de superfícies hidrofóbicas com características autolimpantes a partir de substratos hidrofílicos.

As microesferas de poliestireno 2-aminoetil quando depositadas sobre o substrato polimérico de amido e suas blendas resultaram em ângulos de contato acima de $150^{\circ}$. Da mesma forma, os substratos decorados com nanofibras de PCL também obteve valores próximos e por vezes superiores a $150^{\circ}$ para o ângulo de contato. Neste último caso, o PCL ainda possui a vantagem de ser biodegradável, não interferindo na biodegradabilidade do polímero natural a base de amido de mandioca e suas blendas.

Santos et al. (2017) também estudou a hidrofobicidade em polímeros biodegradáveis. Segundo o autor, nos dias de hoje, os polímeros empregados em embalagens plásticas tradicionais vêm sendo substituídos por filmes poliméricos comestíveis devido a sua biodegradabilidade e biocompatibilidade. Filmes poliméricos a base de quitosana aumentam a vida útil de frutas, pois possuem propriedades antimicrobianas, antifúngicas e antioxidantes. Além do mais, os filmes a base de quitosana são resistentes a gordura e a óleo, e possuem baixa permeabilidade de gases. Contudo, não apresentam resistência à permeabilidade à água, uma vez que a maioria dos polímeros naturais são hidrofílicos.

Santos et al. (2017) conseguiu melhorar as propriedades de barreira à água da quitosana adicionando cera de carnaúba no polímero. Para chegar neste resultado preparou uma solução de quitosana e ácido acético e adicionou glicerol como agente plastificante. A esta solução adicionou a cera de carnaúba nas concentrações de 0 (controle), 15, 30, 40 e 50\% p/p para aumentar seu ângulo de contato. Na sequência, as soluções finais nas variadas concentrações foram transferidas para placas de acrílico e deixadas em repouso por $48 \mathrm{~h}$ a temperatura ambiente para a evaporação dos solventes.

A espessura dos filmes obtidos foi medida com micrômetro onde verificou-se que uma maior concentração de cera de carnaúba nos polímeros aumentava a sua espessura. Os valores partiram de 0,0364 mm para o filme sem a cera, 0,0542, 0,0678, 0,0724 e 0,0858 mm para os filmes com 15, 30, 40 e $50 \%$ de cera respectivamente. A medida que as concentrações de cera de carnaúba e a espessura dos filmes aumentou, a opacidade dos revestimentos também aumentou proporcionalmente. Porém, o aumento da opacidade não foi muito acentuado. O revestimento com $0 \%$ de cera apresentou uma opacidade de $13,56 \%$, enquanto que o revestimento com $50 \%$ de cera apresentou $24,11 \%$ de opacidade em ensaios realizados em colorímetro.

A adição da cera de carnaúba diminuiu a hidrofilicidade dos filmes à base de quitosana. Os valores dos ângulos de contato estão representados na Figura 7. Nota-se que os revestimentos com 0 e $15 \%$ de cera de carnaúba ainda apresentam superfícies hidrofílicas. Já os filmes com 40 e $50 \%$ de 
cera apresentaram ângulos de contato de $78^{\circ}$ e $83^{\circ}$ respectivamente, indicando propriedades superficiais muito próximas a das superfícies hidrofóbicas. Com a transição do caráter hidrofílico para o hidrofóbico, as propriedades de barreira à água dos biofilmes de quitonsana aumentaram significativamente a medida em que a cera de carnaúba foi adicionada.

Figura 7 - Ângulo de contato em função da concentração de cera de carnaúba.

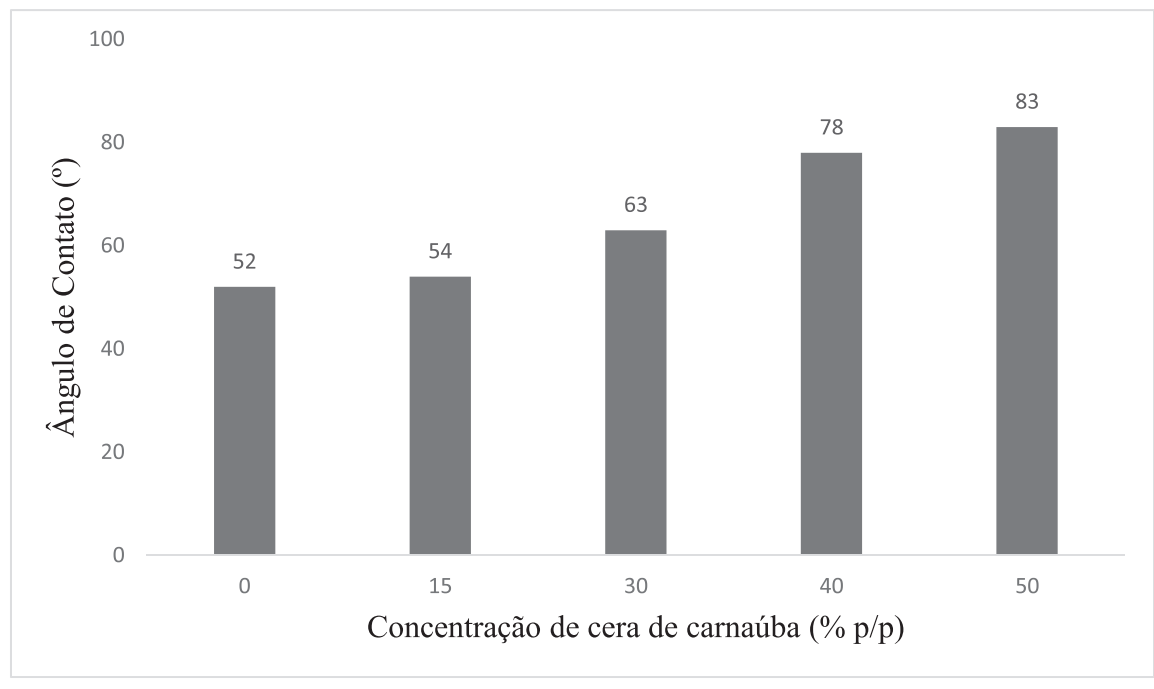

Fonte: Adaptado de Santos e colaboradores (2017).

Picolo e colaboradores (2019) produziram uma superfície super-hidrofóbica e autolimpante a partir da modificação superficial do polimetacrilado de metila (PMMA) usando nanopartículas de sílica funcionalizadas com perfluorooctiltrietoxissilano (POTS). As nanopartículas de sílica possuem hidroxilas e, portando possuem características hidrofílicas, contudo quando funcionalizadas com POTS a sua eletronegatividade aumenta devido a presença do flúor em sua estrutura química, modificando o caráter de hidrofílico para hidrofóbico.

Para avaliar a eficiência das nanopartículas de sílica funcionalizadas com POTS, Picolo e colaboradores (2019) analisaram o PMMA com nanopartículas de sílica, com POTS, com nanopartículas de sílica funcionalizadas com POTS, e compararam com o PMMA sem nenhum tipo de tratamento superficial. As nanopartículas de sílica foram depositadas sopre placas de PMMA por meio de gotejamento de uma solução de $1 \%$ p/p de nanopartículas em acetona. Já a deposição do POTS foi realizada em uma solução de $0,5 \%$ p/p de POTS em etanol.

Para determinar a hidrofobicidade do material, as amostras tiveram sua molhabilidade avaliada em um goniômetro. Os resultados obtidos estão representados na tabela 2, e na figura 8 podemos visualizar os resultados obtidos. Nota-se que o PMMA tratado apenas com nanopartículas de sílica não apresentou resultados de ângulo de contato, comprovando o caráter hidrofílico da sílica. Contudo, quando as nanopartículas foram funcionalizadas com POTS obteve-se um alto ângulo de contato, caracterizando um superfície super-hidrofóbica e autolimpante. 
Tabela 2 - Ângulo de contato avalizado em goniômetro.

\begin{tabular}{lc}
\hline \multicolumn{1}{c}{ Amostra } & Ângulo de contato $\mathbf{(}^{\mathbf{}}$ ) \\
\hline PMMA não tratado & 77,2 \\
\hline PMMA + nanopartículas de sílica & Não determinado \\
PMMA + POTS & 115,7 \\
PMMA + nanopartículas de sílica + POTS & 150,32 \\
\hline \multicolumn{2}{c}{ Fonte: adaptado de Picolo et al. (2019). }
\end{tabular}

Figura 8 - Visualização do ângulo de contato do (A) PMMA não tratado, (B) tratado com nanopartículas de sílica, (C) tratado com POTS, e (D) tratado com nanopartículas de sílica funcionalizadas com POTS.

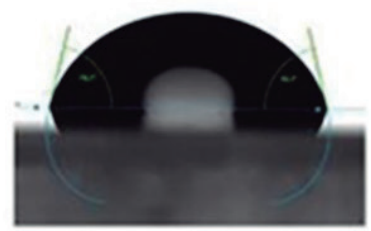

(A)

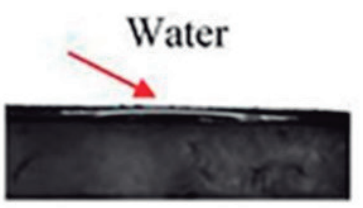

(B)

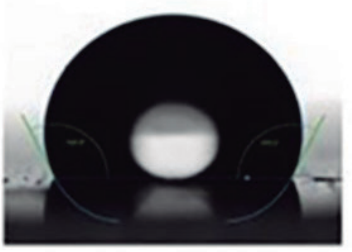

(C)

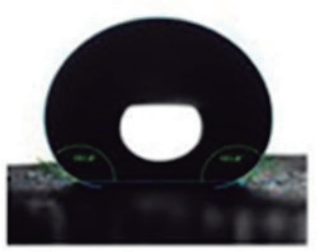

(D)

Fonte: Adaptado de Picolo e colaboradores (2019).

As propriedades autolimpantes também foram verificadas sobre a superfície do PMMA tratado com as nanopartículas de sílica funcionalizadas com POTS. Nesta análise $10 \mathrm{mg}$ de carvão em pó foram espalhadas sobre o substrato tratado (Figura 9 A). Na sequência, gotas de $10 \mu \mathrm{L}$ foram depositadas sobre a superfície do polímero e o mesmo foi inclinado para que as gotas pudessem rolar e remover as impurezas (Figura 9 B). Por último, uma análise foi feita da mesma forma do procedimento anterior, porém sem inclinar a superfície (Figura $9 \mathrm{C}$ ). Pode-se notar que mesmo com as gotas estáticas, o carvão é adsorvido da superfície do polímero pela água, comprovando se tratar de uma superfície autolimpante.

Figura 9 - Verificação de propriedades de autolimpeza do PMMA tratado com nanopartículas de sílica funcionalizadas com POTS.

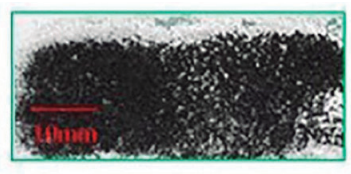

(a)

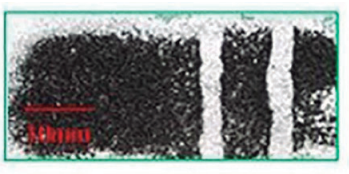

(b)

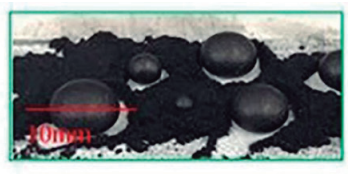

(c)

Fonte: Picolo et al. (2019).

\section{PESQUISA EXPLORATÓRIO BIBLIOGRÁFICA DE SUPERFÍCIES HIDROFÓBICAS}

Batista, Segundo e Silva (2019) fizeram um monitoramento tecnológico sobre o desenvolvimento de superfícies com caráter hidrofóbico nas diversas áreas de aplicações por meio da análise de 
patentes. Assim, foram analisados 400 documentos diferentes sobre o assunto, todos eles oriundos da plataforma Questel Orbit ${ }^{\circledR}$, sistema que abrange bases de dados de patentes de vários países, como o Escritório Americano de Marcas e Patentes (USPTO), Escritório Europeu de Patentes (EPO), Instituto Nacional de Propriedade Industrial (IMPI) do Brasil, entre outros.

Assim, dentre 1998-2018, foram publicadas 393 patentes relativas a superfícies hidrofóbicas. Houve um aumento significativo no número de patentes publicadas a partir do ano de 2013, e no ano de 2017 foi registrado o maior número de patentes publicadas, num total de 44 patentes. A evolução anual de registro de patentes sobre superfícies hidrofóbicas pode ser observada na Figura 10. Quando comparado o número de patentes publicadas por empresas e por centros de pesquisa, notou-se que $80 \%$ das patentes são de empresas e, apenas $20 \%$, são de centros de ensino. As empresas que mais se destacam no registro de patentes ficam localizadas no Japão, Alemanha e Estados Unidos. Já na área do ensino, os cinco principais centros de ensino e universidades que mais publicaram sobre o assunto ficam sedeados na China.

Figura 10 - Evolução na publicação do número de patentes por ano.

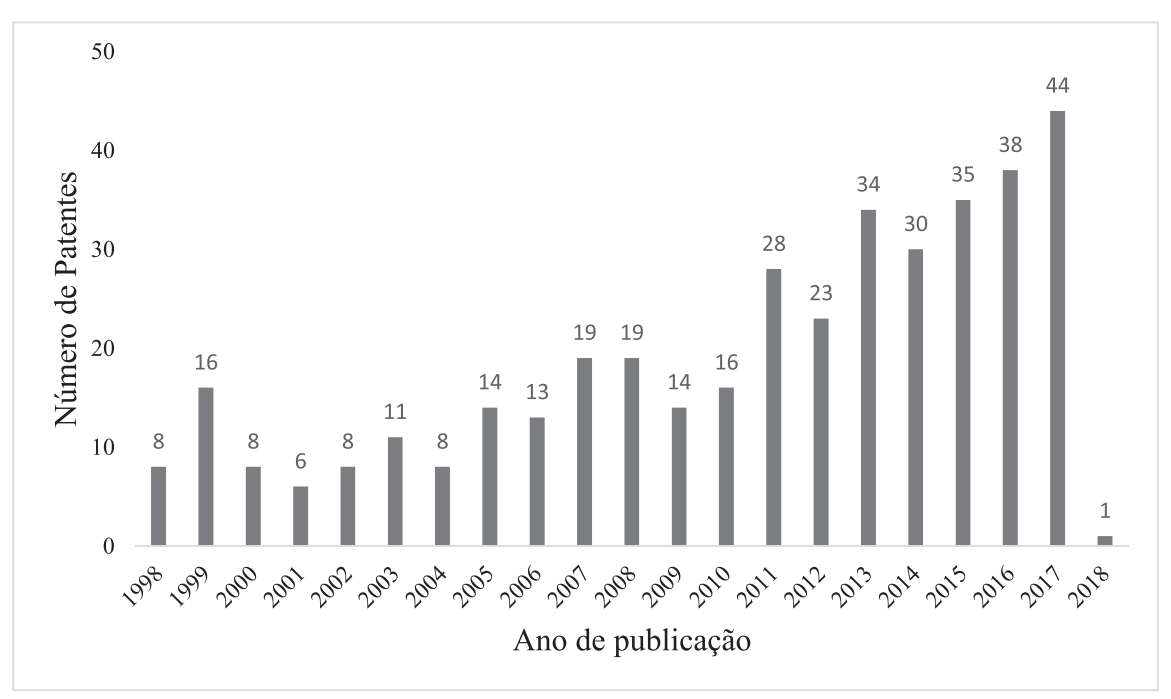

Fonte: Batista, Segundo e Silva (2019).

Os países que mais publicaram patentes sobre os revestimentos foram China com $26,54 \%$ das publicações, seguida dos Estados Unidos com 8,89\% e do Japão com 6,84\%. Contudo, quando se analisa o número de patentes depositadas por país, a porcentagem para China, Estados Unidos e Japão é de 23\%,20\% e 18\%, respectivamente. Ao se analisar a área tecnológica relacionada as publicações de superfícies hidrofóbicas, os polímeros figuram em segundo lugar, com 14\% das publicações no período estudado, ficando atrás apenas de materiais químicos básicos, que obtiveram $20 \%$ dos registros. Isso comprova que os polímeros estão entre as principais matérias-primas para a produção de revestimentos hidrofóbicos. 


\section{CONCLUSÃO}

Baseado nos resultados obtidos por meio das pesquisas realizadas pode-se verificar que existem inúmeras formas de produção de revestimentos poliméricos para a produção de superfícies hidrofóbicas, super-hidrofóbicas ou autolimpantes para as mais diversas aplicações. Além disso, verificou-se também que é possível modificar a superfície dos polímeros para a obtenção de maiores ângulos de contato.

Filmes poliméricos hidrofóbicos para revestimento de vidros podem ser produzidos pela técnica de deposição à vapor químico assistido por plasma (PECVD) assim como o proposto por Souza (2018), ou por métodos mais simples como solubilização de um polímero em solvente adequado e aplicação do produto por borrifamento, técnica esta desenvolvida por Viechineski (2015).

Modificações superficiais em polímeros podem resultar em superfícies super-hidrofóbicas e autolimpantes. Avancini (2018) e Picolo et al. (2019) conseguiram excelentes valores de ângulo de contato para revestimentos super-hidrofóbicos modificando superficialmente os polímeros empregados nos substratos. Gama (2014) e Santos (2017) estudaram a mudança de caráter hidrofílico para hidrofóbico de polímeros biodegradáveis modificados superficialmente, visando aumentar seus ângulos de contato e viabilizar a aplicação dos mesmo como revestimentos comestíveis para alimentos.

Por fim, Batista, Segundo e Silva (2019) fizeram uma análise histórica da evolução dos revestimentos hidrofóbicos entre os anos de 1998 e 2018. O número de pesquisas aumentou durante os anos estudados, sendo que a partir de 2013 este aumento foi ainda mais expressivo. Os autores também concluíram que China, Estados Unidos e Japão são os países que mais se destacam em pesquisas e patentes relacionadas ao tema.

\section{REFERÊNCIAS}

ARAÚJO, R. C. Revestimento superhidrofóbico de nanocompósito PTFE/CaO fabricado por deposição de espuma em fibras de PLA. 2017. Tese de Doutorado - Programa de Pós-Graduação em Engenharia Mecânica, Universidade Federal do Rio Grande do Norte, Natal, 2017.

AVANCI, M. A. Modificação superficial de polietileno visando aumento de hidrofobicidade. 2018. Dissertação - Programa de Pós-Graduação em Engenharia e Ciência dos Materiais, Universidade Federal do Paraná, Curitiba, 2018.

BATISTA, T. S.; SEGUNDO, V.A. G.; SILVA, J. Estudo e Monitoramento Tecnológico de Tecnologias Associadas a Superfícies Hidrofóbicas. Cadernos de Prospecção, Salvador, v. 12, p. 348-359, 2019. 
DAOUD, Walid A. (ed). Self-cleaning: Materials and Surfaces. A Nanotechnology Approach. New Jersey: John Wiley \& Sons, Ltd, 2013.

FOWKES, Frederick (ed.). Hydrophobic Surfaces. New York: Academic Press, 1969.

GAMA, R. de O. Controle do comportamento hidrofílico/hidrofóbico de polímeros naturais biodegradáveis através da decoração de superfícies com nano e microcomponentes. 2014. Tese de Doutorado - Programa de Pós-Graduação em Engenharia Metalúrgica, Materiais e de Minas, Universidade Federal de Minas Gerias, Belo Horizonte, 2014.

HE, Junhui (ed). Self-cleaning Coatings: Structure, Fabrication and Aplication. Cambridge: The Royal Society of Chemistry, 2017;

LAW, Kock-Yee; ZHAO, Hong. Surface Wetting: Characterization, Contact Angle, and Fundamentals. New York: Springer, 2015;

NANOMATERIAIS. Wordpress. Sobre nanomateriais, nanociência e nanotecnologia de forma mais insana. Disponível em: https://bit.ly/39HeJLV. Acesso em: 8 de nov de 2019;

OLIVEIRA, M. R. da S. Superfícies super-hidrofóbicas obtidas através de microestruturas litográficas. 2011. Tese de Doutorado - Escola Politécnica, Universidade de São Paulo, São Paulo, 2011;

PICOLO, N. et al. Sol-gel processed Superhydrofhobic Plastic Surfaces Modified with Perfluorooctyltriethoxysilane (POST). Materials Research. São Carlos, v. 22, 2019;

SANTOS, F. K1. G.. et al. Effect of the Addition of Carnauba Wax on Physicochemical Properties of Chitosan Films. Materials Research, São Carlos, v. 20, p. 479-484, 2017;

SOUZA, D. A. Deposição de filmes poliméricos com micro-jatos atmosféricos. 2018. Dissertação - Faculdade de Engenharia, Universidade Estadual Paulista, Guaratinguetá, 2018;

SOUZA, H. C.; BRAGA, M. E. M.; SOSNIK, A. Biomateriales aplicados al diseño de sistemas terapêuticos avanzados. Coimbra: Imprensa da Universidade de Coimbra, 2015; 
VERPLACK, N. et al. Wettability switching techniques on superhydrophobic surfaces. New York: Springer, 2007;

VIECHINESKI, F. N. Preparação e caracterização de filme transparente polimérico hidrofóbico para aplicação em superfícies de vidro. 2015. Dissertação - Programa de Mestrado em Engenharia de Produção, Universidade Tecnológica Federal do Paraná - Campus Ponta Grosa Ponta Grossa, 2015)

YUAN, Y.; LEE, T. R. Contact Angle and Wetting Properties. Berlin: Springer, 2013. 